\title{
Yearly Trends in Fetal Macrosomia among Hospital Births in Enugu, South East Nigeria
}

\author{
Iyoke $\mathrm{CA}^{1, *}$, Lawani $\mathrm{OL}^{2}$, Ugwu GO ${ }^{1}$, Ezugwu $\mathrm{FO}^{3}$, Ilechukwu GC ${ }^{4}$ \\ ${ }^{1}$ Department of Obstetrics and Gynaecology, University of Nigeria Teaching Hospital, Ituku- Ozalla, Enugu \\ ${ }^{2}$ Department of Obstetrics and Gynaecology, Federal Teaching Hospital, Abakaliki \\ ${ }^{3}$ Department of Obstetrics and Gynaecology, Enugu State University Teaching Hospital, Park Lane, Enugu \\ ${ }^{4}$ Department of Paediatrics, Whiston Hospital, St Helen's and Knowsley Teaching Hospitals NHS Trust, Prescot, United Kingdom \\ *Corresponding author: caiyoke@yahoo.co.uk
}

Received August 17, 2014; Revised August 24, 2014; Accepted August 27, 2014

\begin{abstract}
Fetalmacrosomia is associated with higher risks of maternal and neonatal complications and with health risks in adulthood. Trends in fetal macrosomia could indicate fetal growth patterns and its knowledge could be useful for prenatalcare and maternal health education. The objective of the study was to describe the yearly trends in the prevalence of fetal macrosomia among singleton live term hospital births in Enugu, South East Nigeria. Routinely collected delivery data of three major maternity centres in Enugu were reviewed for the period January 2003 to December 2013. All singleton term live births that took place at the three centres during the study period were analysed and the yearly prevalences of fetal macrosomia were determined. Statistical analysis involved descriptive and inferential statistics at 95\% level of confidence. A total of 22,628 singleton live term deliveries were studied. There were 2116 births of macrosomic babies giving a prevalence rate of 9.3\% of singleton term deliveries. The mean weight of all macrosomic babies was $4.42 \mathrm{~kg} \pm 0.38$. The prevalence rates of macrosomia showed a small, but significant decreasing trend over the period of study. The likelihood of fetal macrosomia was increased by male births (aOR 1.64, 95\% confidence interval [C.I.] 1.10, 3.20); postdate births (aOR 2.1, 95\% C.I. 1.4, 4.1) and multiparity (aOR 8.0, 95\% C.I. 3.2, 16.4). It was concluded that there was a decreasing trend in the prevalence of fetal macrosomia in the study centres,and factors such as the prevalences of male births, postdate pregnancies and multiparity could have influenced this, at least in part. However, population based studies incorporating prenatal weight and medical complication data would be needed to establish the factors responsible for the actual trend in macrosomic births in the general population in this area.
\end{abstract}

Keywords: fetal macrosomia, trend, birth weight, prevalence, Nigeria

Cite This Article: Iyoke CA, Lawani OL, Ugwu GO, Ezugwu FO, and Ilechukwu GC, "Yearly Trends in Fetal Macrosomia among Hospital Births in Enugu, South East Nigeria.” American Journal of Clinical Medicine Research, vol. 2, no. 4 (2014): 79-83. doi: 10.12691/ajcmr-2-4-4.

\section{Introduction}

Fetal macrosomia, defined as birth weight greater than or equal to $4 \mathrm{~kg}$, has been associated with increased maternal and fetal complications during delivery [1]. These complications include low Apgar scores, birth injuries, fresh stillbirths, shoulder dystocia, prolonged labour, obstructed labour, uterine rupture genital tract lacerations and postpartum haemorrhage [1,2,3,4]. Maternal risk factors for macrosomia include advancing maternal age, high parity, maternal obesity, diabetes in pregnancy, previous history of macrosomia, maternal tall height, and excessive pregnancy weight gain while fetal risk factors include postdatism, male sex [1,2,3,4].

Reports show that the trends in the prevalence of fetal macrosomia vary across different regions of the world with contrasting trends in the occurrence of macrosomia reported from the USA, Asia and Europe. A decreasing trend in fetal macrosomia in the USA has been ascribed to decrease in fetal growth [5]. However, a report from Sweden indicatedan increase in fetal macrosomia which was attributed to increases in maternal body mass indices and decrease in smoking among pregnant women [6]. Similarly a studyfrom China showed an increase in macrosomia due to increase in net gestational weight gain [7]. Although several studies from our area have demonstrated increased feto-maternal complications in births involving macrosomic babies $[8,9,10]$, we found no studies on the trends in the prevalence of fetal macrosomia in South East Nigeria. The aim of this study was to describe the temporal trends in the prevalence of fetal macrosomia among singleton term hospital births in Enugu, South East Nigeria in the last decade.

\section{Methodology}

The study centres included two teaching hospitals in Enugu namely the University of Nigeria Teaching hospital Ituku-Ozalla, and the Enugu State University Teaching 
Hospital, Park Lane and a private specialist maternity hospital, St Patrick's Hospital, Asata, Enugu. The study centres were selected on account of convenience and because of the availability of good routine delivery records for the period of study. The three hospitals have a combined annual delivery rate of 2000- 3000 deliveries. All births were routinely recorded in a chronological order in a delivery register which served as delivery database ineach of the study centres. Delivery registers were manually kept and had patient information including date of delivery, folio number, age, parity, booking status, gestational age at delivery, mode/route of delivery, birth weight, fetal sex, Apgar scores in the $1^{\text {st }}$ and $5^{\text {th }}$ minutes, postpartum blood loss, placental weight and information on admission to the New Born Special Care Unit(NBSCU). Data on maternal occupation, educational status, weight and medical complications of pregnancy were not routinely recorded in delivery registers.

A retrospective quantitative review study design was used to study all singleton term deliveries that took place over the period from January $1^{\text {st }} 2003$ to December $31^{\text {st }}$ 2013.Information on maternal booking status, age, mode of delivery, gestational age at delivery, parity, fetal birth weight and fetal sex were collected from delivery registers. The pooled data were coded into SPSS version 17.0 for Windows and Microsoft Excel for analysis with descriptive and inferential statistics at 95\% level of confidence. The main outcome variable was the yearly prevalence of fetal macrosomia. For this study, macrosomia was defined as birth weight equal to or greater than 4 kilograms. In all the hospitals, gestational age was calculated based on the last day of the woman's normal menstrual period. Women who were unsure of date had their gestational ages determined by ultrasound scans. Postdate delivery was defined as delivery that occurred after the expected date of delivery. The prevalence of macrosomic babies was computed for each year by dividing the number of deliveries involving macrosomic babies by the total number of singleton term births for that year. A line chart for the yearly trends in fetal macrosomia was obtained with Microsoft Excel Software.

Poisson regression was used to analyse the yearly trends in the prevalences of macrosomia. The results were reported as p-values of Wald coefficients with 95\% confidence limits. Similarly logistic regression was done to determine the factors that predicted fetal macrosomia using fetal sex, parity, gestational age, route of delivery, booking status, and maternal age as explanatory variables. The results of logistic regression were reported as adjusted odd s ratios with $95 \%$ confidence limits. For all analyses, $\mathrm{P}$ values equal to or less than 0.05 were considered significant. Missing values were excluded at every step of the analysis; therefore the results without missing values were presented. Ethical consent for the study was obtained from the research ethics committees of the University of Nigeria Teaching Hospital and Enugu State University Teaching Hospital.

Table 1. Showing a comparison of the characteristics of women who had singleton deliveries from 2003 to 2013 at UNTH Enugu ${ }^{a}$

\begin{tabular}{|c|c|c|c|}
\hline \multirow{2}{*}{ Characteristic } & \multicolumn{2}{|c|}{ Frequency (\%) } & \multirow{2}{*}{ p-value } \\
\hline & Singleton term non-macrosomic deliveries $(n=20612)$ & Singleton term Macrosomic deliveries $(n=2016)$ & \\
\hline Age & $n=20592$ & $n=2004$ & \\
\hline$<35$ year & 10433(50.7) & $881(44.0)$ & 0.49 \\
\hline$\geq 35$ years & 10159(49.3) & 1123(56.0) & \\
\hline Parity & $\mathrm{n}=20612$ & $n=2014$ & \\
\hline nulliparous or primiparous & $16116(78.2)$ & $512(25.4)$ & $\begin{array}{c}<0.001 \\
*\end{array}$ \\
\hline multiparous & 4496 (21.8) & 1502(74.6) & \\
\hline Gestational age at delivery & $\mathrm{n}=20499$ & $\mathrm{n}=2016$ & \\
\hline 37-40 weeks & $19269(94.0)$ & 1899(94.2) & 1.00 \\
\hline After 40 weeks & $1230(6.0)$ & $117(5.8)$ & \\
\hline Booking status & $\mathrm{n}=20612$ & $\mathrm{n}=1974$ & \\
\hline booked & $17727(86.0)$ & $1596(80.9)$ & 0.34 \\
\hline unbooked & 2886(14) & 378 (19.1) & \\
\hline Mode of delivery & $n=20612$ & $n=2016$ & \\
\hline vaginal & $12780(62.0)$ & 1102 (54.7) & 0.32 \\
\hline caesarean & 7832(38.0) & 914 (45.3) & \\
\hline APGAR score & $\mathrm{n}=19320$ & $\mathrm{n}=1866$ & \\
\hline 1 minute $\leq 7$ & $540(2.8)$ & $234(12.5)$ & $0.01^{*}$ \\
\hline 5 minutes $\leq 7$ & $321(1.8)$ & $98(5.2)$ & \\
\hline Fetal sex & $n=20612$ & $n=2016$ & \\
\hline Male & $10100(49.0)$ & 1069(53) & 0.57 \\
\hline female & $10512(51.0)$ & $947(47.0)$ & \\
\hline $\begin{array}{l}\text { Estimated blood loss for } \\
\text { vaginal deliveries }\end{array}$ & $n=12780$ & $n=1102$ & \\
\hline$<500 \mathrm{mls}$ & $11690(91.5)$ & $970(88.0)$ & $0.03 *$ \\
\hline$\geq 500 \mathrm{mls}$ & $1090(8.5)$ & 132 (22.0) & \\
\hline
\end{tabular}

${ }^{\mathrm{a}}$ Pooled data from three maternity centres in Enugu. 


\section{Results}

\subsection{Characteristics of Index Singleton Term Birth Cohort}

The birth records of 22,628 singleton term deliveries were analysed. The mean age of mothers who delivered singleton babies was $30.4 \pm 2.3$ years (range 15-46 years). The mean gestational age at delivery was 38.6 weeks (range 37-44weeks) whereas the mean weight of all singleton babies was $4.15 \pm 0.8 \mathrm{~kg}$ (range $2.3-5.5 \mathrm{~kg}$ ). The mean parity of mothers who delivered singleton babies was 3.3 (range $0-8$ ). On the average, approximately 51\% of singleton deliveries involved male births and $8.0 \%$ of all singleton deliveries occurred post term. The average caesarean section rate for the study period was $38 \%$. Table 1 shows a comparison of the sociodemographic characteristics of parturients who delivered singleton babies at term during the study period.

\subsection{Macrosomic Singleton Term Births}

\subsubsection{Prevalence}

2116 of the singleton term deliveries involved macrosomic babies giving the prevalence of fetal macrosomia over the study period as $9.3 \%$ of term singleton deliveries. The records of 2016 macrosomic deliveries were available for analysis. The mean weight of all macrosomic babies was $4.42 \mathrm{~kg} \pm 0.38$ (range $4.0-5.5 \mathrm{~kg}$ ). Approximately $7.6 \%$ of women who delivered macrosomic babies were at the extremes of reproductive age; $25 \%$ were nullipara or primipara.

\subsubsection{Yearly Trends in Prevalence of Macrosomia}

As shown in Table 2 the prevalence of macrosomia decreased from $9.8 \%$ in 2003 to $9.0 \%$ in 2005 before rising sharply to $11.5 \%$ in 2008 . Thereafter it dropped steadily to $7.5 \%$ in 2010 before rising to $9.4 \%$ in 2012 . However, it subsequently dropped to $7.9 \%$ in 2013.
Overall between 2003 and 2013, there was a slight decrease in the prevalence of macrosomia. Table 2 shows the yearly prevalences of macrosomia based on the total singleton term birth cohort while Figure 1 is a line graph to illustrate the temporal trend in the prevalence of macrosomia.

Table 2. Yearly prevalences of macrosomia among singleton term deliveries at UNTH Enugu from 2003-2013 ${ }^{\mathrm{a}}$

\begin{tabular}{|c|c|c|}
\hline Year & Total births & Macrosomia (\%) \\
\hline 2003 & $1112^{\mathrm{b}}$ & $109(9.8)$ \\
\hline 2004 & $1890^{\mathrm{b}}$ & $181(9.6)$ \\
\hline 2005 & $1001^{\mathrm{b}}$ & $90(9.0)$ \\
\hline 2006 & $845^{\mathrm{b}}$ & $97(11.5)$ \\
\hline 2007 & $919^{\mathrm{b}}$ & $87(9.5)$ \\
\hline 2008 & 2987 & $278(9.3)$ \\
\hline 2009 & 3008 & $272(9.0)$ \\
\hline 2010 & 2943 & $221(7.5)$ \\
\hline 2011 & 2192 & $183(8.3)$ \\
\hline 2012 & 3052 & $287(9.4)$ \\
\hline 2013 & 2679 & $211(7.9)$ \\
\hline \multicolumn{2}{|c|}{ pooled data from three maternity centres, ${ }^{\text {b }}$ data from UNTH only } \\
\hline
\end{tabular}

Table 3. Poisson regression to determine significance of yearly changes in the prevalence of macrosomia

\begin{tabular}{|c|c|c|c|c|}
\hline \multirow{2}{*}{ Year $^{c}$} & \multirow{2}{*}{ B } & \multicolumn{2}{|c|}{$\begin{array}{c}\text { 95\% Confidence intervalfor Wald } \\
\text { estimate }\end{array}$} & \multirow{2}{*}{ p-value } \\
\cline { 3 - 4 } & & $\underline{\text { lower }}$ & upper & \\
\hline 2013 & -735.8 & -736.7 & -743.8 & $<0.001^{*}$ \\
\hline 2012 & -882.8 & -883.7 & -881.8 & $<0.001^{*}$ \\
\hline 2011 & -509.9 & -510.8 & -508.9 & $<0.001^{*}$ \\
\hline 2010 & -531.6 & -532.5 & -530.7 & $<0.001^{*}$ \\
\hline 2009 & -330.7 & -331.6 & -329.8 & $<0.001^{*}$ \\
\hline 2008 & -890.7 & -891.7 & -889.8 & $<0.001^{*}$ \\
\hline 2007 & -328.9 & -329.8 & -327.9 & $<0.001^{*}$ \\
\hline 2006 & 210.1 & 209.1 & 211.1 & $<0.001^{*}$ \\
\hline 2005 & 529.0 & 528.0 & 530.0 & $<0.001^{*}$ \\
\hline 2004 & -372.9 & -373.8 & -371.9 & $<0.001^{*}$ \\
\hline 2003 & $0^{\mathrm{a}}$ & - & - & - \\
\hline
\end{tabular}

*significant ${ }^{\text {a }}$ reference variable, ${ }^{\mathrm{c}}$ pair-wise contrasts of yearly prevalences

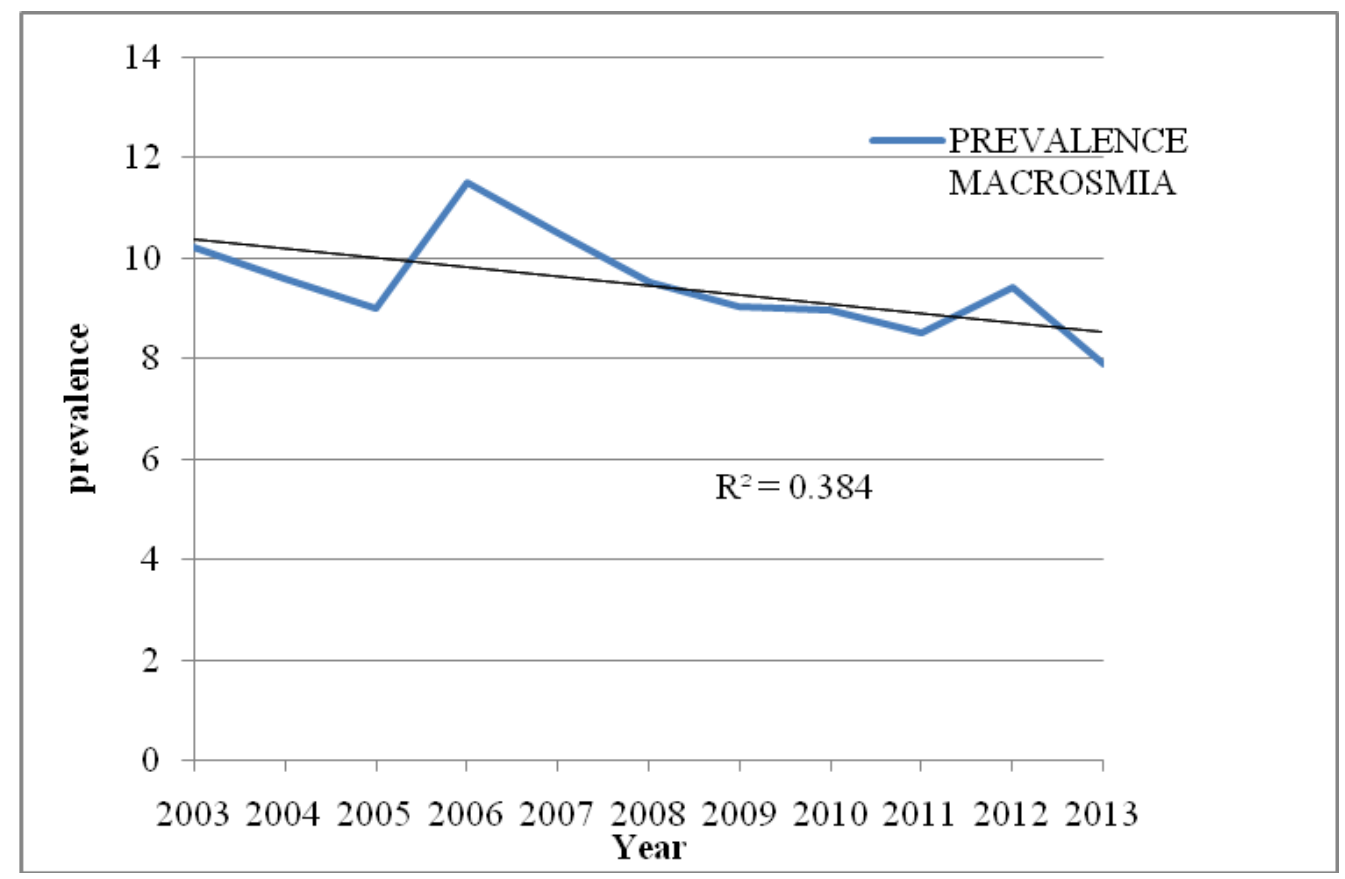

Figure 1. Showing plots of the trend in the prevalence of fetal macrosomia over the period 2003-2013 
Table 3 summarizes the Poisson regression analysis to determine the significance of yearly changes in the prevalence of macrosomia. Model parameter estimates showed that yearly differences in the prevalence of macrosomia across the study period were statistically significant. And except for 2005 and 2006, for every change in year there was a statistically significantdecrease in the prevalence of fetal macrosomia.

\subsubsection{Factors Associated with the Trends in Fetal Macrosomia}

Table 4 shows Poisson regression analysis to determine the factors associated with the trend in the prevalence of macrosomia. Male fetal sex, postdate pregnancy and multiparity all increased the likelihood of fetal macrosomia while route of delivery, booking status and maternal age category had no significant predictive effect.

Table 4. Results of logistic regression to determine the delivery characteristics that predicted fetal macrosomia $\ddagger$

\begin{tabular}{|c|c|c|c|c|c|}
\hline \multirow{2}{*}{ parameter } & \multirow{2}{*}{ B coefficient } & \multirow{2}{*}{ Odds ratio } & \multicolumn{2}{|c|}{ 95\% Confidence interval For Wald estimate } & \multirow{2}{*}{ p-value } \\
\hline & & & lower & upper & \\
\hline \multicolumn{6}{|l|}{ Fetal sex } \\
\hline Male & 19.04 & 1.64 & 1.10 & 3.20 & $0.01^{*}$ \\
\hline Female & $0^{\mathrm{a}}$ & & - & - & - \\
\hline \multicolumn{6}{|l|}{ Gestational age at delivery } \\
\hline Postdate & 14.12 & 2.10 & 1.40 & 4.10 & $0.03^{*}$ \\
\hline Term & $0^{\mathrm{a}}$ & & - & - & - \\
\hline \multicolumn{6}{|l|}{ Parity } \\
\hline Multipara & 59.01 & 8.00 & 3.20 & 16.50 & $<0.01^{*}$ \\
\hline Nullipara or primipara & $0^{\mathrm{a}}$ & & - & - & - \\
\hline \multicolumn{6}{|l|}{ Route of delivery } \\
\hline Caesarean & -181.00 & 0.32 & 0.02 & 1.25 & 0.22 \\
\hline Vaginal & $0^{\mathrm{a}}$ & & - & - & - \\
\hline \multicolumn{6}{|l|}{ Booking status } \\
\hline Unbooked & -0.22 & 0.81 & 0.70 & 1.15 & 0.64 \\
\hline Booked & $0^{\mathrm{a}}$ & & - & - & - \\
\hline \multicolumn{6}{|l|}{ Maternal age (years) } \\
\hline$\geq 35$ years & 0.58 & 0.68 & 0.24 & 1.90 & 0.17 \\
\hline$<35$ years & $0^{\mathrm{a}}$ & - & - & - & - \\
\hline
\end{tabular}

* significant ${ }^{\mathrm{a}}$ reference variable, $\ddagger$ data from UNTH and ESUTH only

\section{Discussion}

This was the first study to explore the trends in fetal macrosomia among hospital births in Enugu, South East Nigeria. The study relied on data obtained from the delivery databases of major maternity centres in the city: a study based on information from case notes of all singleton deliveries in the three hospitals for ten years would have been impossible due to poor upkeep of manually-kept records. Besides, afacility-based study of macrosomia [11] was necessitated by the absence of community-based population birth registers in our area for most of the study period. Although birth registration is now legally required for all births in Nigeria, the enabling law is not fully enforced and registration of births is far from comprehensive.

This study found that the prevalence of fetal macrosomia over the period was similar to the prevalence of $8.1 \%$ obtained in a hospital-based study in Benin, South-South Nigeria in 2006 [9]. In the same vein, the findings of higher prevalence of macrosomiaamong multiparous parturients are similar to the findings in studies conducted in Ibadan, Aba, Lagos and Benin all in Nigeria [9,12,13]. The similarity in the pattern of macrosomia between this study and previous ones in other ethnic groups in Nigeria suggest that the occurrence of macrosomia may not differ significantly across tribes in Nigeria.
The prevalences of macrosomia showed a slight but significant decreasing trend over the study period. A decreasing trend in fetal macrosomia among urban dwellers was an unexpected finding given the generally held perception that obesity among women was increasing in developing countries such as Nigeria [14,15]. Besides from anecdotal evidence, smoking among pregnant women which is known to reduce fetal weight is still a rarity in Nigeria. The finding of decreasing trend in fetal macrosomia, however, agrees with population-based studies by Morisaki and colleagues in the US [5] but contrasts with those of studies in China and Sweden [6,7]. The decreasing trend found in this study needs to be interpreted with caution because of the hospital-based nature of the study. However, the result provides a basis for future population-based study in this area to determine the actual trend in the general population.

With respect to an explanation for this observed trend, the design of this study would be inadequate since important factors that could impact fetal macrosomia such as maternal diabetes mellitus, excessive weight gain in pregnancy and maternal body mass index were not included in the explanatory variables because they were not captured in delivery registers. However, based on the limited data in the delivery registers, this study found that fetal and maternal characteristics such as fetal sex, postdatism and multiparity all had positive predictive effects on fetal macrosomia. The trends in their prevalences could have affected the trend in macrosomia. 
The strengths of this study include the use of multiple institutions (including private and public maternity centres) within the city to increase the coverage of all segments of the society and thus improve the external validity of the findings of the study. The limitations of this study include the fact that while the study was based on hospital deliveries, most deliveries occur outside health facilities in Nigeria. A population based study would have taken care of deliveries outside health facilities. Besides, deficiencies in the range of routine data included in hospital delivery databases were such that the prevalences of indices such as gestational weight gain, prepregnancy body mass indices, and medical conditions such as obesity and gestational diabetes, all of which are known to impact fetal weight could not be assessed.

We conclude that the study suggests a slow and gradual overall declining trend in the prevalence of macrosomia among singleton term hospital births in the study centres which was probably influenced, at least in part, by the prevalences of male births, multiparity and postdate deliveries. We recommend a population-based study to establish the actual trend of fetal macrosomia in this society. Modification and improvement in current birth registration data capture proforma of the National Population Commission of Nigeria in order to include important maternal and fetal medical data that would enable future comprehensive population-based studies to determine both the trends as well as factors associated with fetal macrosomia in this area.

\section{Conflict of Interests}

The authors have no conflict of interests arising from this work.

\section{Acknowledgements}

The authors acknowledge the contributions of Dr C. Eze and Dr Nevo as well as the nursing and medical records staff of the maternity wards of the UNTH and Enugu State University Teaching Hospital who assisted with data collection for this study.

\section{References}

[1] Ezegwui HU, Ikeakor LC, Egbuji C. Fetal macrosomia: obstetric outcome of 311 cases at UNTH, Enugu, Nigeria. Nig J Clin Pract, 2011; 14: 322-6.

[2] Lao TT, Cheng KY. Fetal and maternal complications in macrosomic pregnancies. Research and Reports in Neonatology, 2014: 4 65-70.

[3] Najafian M, Cheraghi M. Occurrence of Fetal Macrosomia Rate and Its Maternal and Neonatal Complications: A 5-Year Cohort Study. ISRN Obstetrics and Gynecology, 2012.

[4] Mohammadbeigi A, Farhadifar F, Soufi zadeh NS, Mohammadsalehi N, Rezaiee M, Aghaei M. Fetal macrosomia: Risk factors, Maternal, and Perinatal outcome. Ann Med Health Sci Res, 2013; 3: 546-50.

[5] Morisaki N, Esplin MS, Varner MW, Henry E, Oken E. Declines in birth weight and fetal growth independent of gestational length. Obstet Gynecol, 2013; 121(1): 51-8.

[6] Surkan PJ, Hsieh CC, Johansson AL, Dickman PW, Cnattingius S. Reasons for increasing trends in large for gestational age births. Obstet Gynecol, 2004; 104(4): 720-6.

[7] Lu Y, Zhang J, Lu X, Xi W, Li Z. Secular trends of macrosomia in southeast China, 1994-2005. BMC Public Health, 2011, 11:818.

[8] Kamanu C T, Chigbu B, Aluka C. Foetal macrosomia in an African population; a study of 249 cases. Arch Gynecol Obstet 2009; 279 (6); 857-61.

[9] Onyiruka A N, High birth weight babies: incidence and foetal outcome in a mission hospital in Benin city, Niger J Clin Pract 2006, 9: 14-9.

[10] Megafu U, Ozumba B C. Obstetric complications of macrosomic babies in African women, Int J Gynaecol Obstet 1988, 26(2): 997207.

[11] Koyanagi A, Zhang J, DagvadorjA, Hirayama F, Shibuya K, Souza JP et al.Macrosomia in 23 developing countries: an analysis of amulticountry, facility-based, cross-sectional survey. Lancet 2013; 381: 476-83

[12] Abudu O O, Awonuga A O, Foetal macrosomia and pregnancy in Lagos. Int J Gynecol, 1989; 28 (3): 257-62.

[13] Lawoyin T O, A prospective study on some factors which influence the delivery of large babies, J Trop Med Hyg 1993, 96 (6); 352-6.

[14] Akarolo-Anthony SN, Willett WC, Spiegelman D, Adebamowo C. Obesity epidemic hasemerged among Nigerians. BMC Public Health 2014 14: 455.

[15] Chukwuonye 11, Chuku A, John C, Ohagwu KA, Imo ME, Isa SE et al. Prevalence of overweight and obesity in adult Nigerians - a systematic review. Diabetes, Metabolic Syndrome and Obesity: Targets and Therapy, 2013: 6 43-47. 